\title{
Psychometric Properties of OPMH-40, a Survey for the Evaluation of the Occupational Positive Mental Health
}

\author{
Julio César Vázquez-Colunga1, Manuel Pando-Moreno', Cecilia Colunga-Rodríguez ${ }^{1,2}$ \\ ${ }^{1}$ University Center for Health Sciences, University of Guadalajara, Guadalajara, Mexico \\ ${ }^{2}$ Pediatric Hospital of the National West Medical Center at the Instituto Mexicano del Seguro Social (Mexican Social Security \\ Institute, or IMSS), Guadalajara, Mexico \\ Email: cecilia.colunga@imss.gob.mx
}

How to cite this paper: Vázquez-Colunga, J. C., Pando-Moreno, M., \& ColungaRodríguez, C. (2017). Psychometric Properties of OPMH-40, a Survey for the Evaluation of the Occupational Positive Mental Health. Psychology, 8, 424-435.

https://doi.org/10.4236/psych.2017.83026

Received: December 27, 2016

Accepted: February 24, 2017

Published: February 27, 2017

Copyright (c) 2017 by authors and Scientific Research Publishing Inc. This work is licensed under the Creative Commons Attribution International License (CC BY 4.0).

http://creativecommons.org/licenses/by/4.0/

\section{Open Access}

\begin{abstract}
The aim of this study was to determine the psychometric properties of a measurement instrument design for the evaluation of the occupational positive mental health. Based on the positive psychology, humanism, salutogenesis and ecological model, we developed a 40 items survey with a five-point Liker response option. A sample of 740 workers of different occupations answered the survey, taking an average of 15 minutes. The data analysis included exploratory factor analysis for the determination of factorial validity and Cronbach's Alpha coefficient for reliability. The results indicated a four-factor structure that explains $43.55 \%$ of the total variance and a Cronbach's Alpha of .923 for the whole instrument. We conclude that the SMPO-40 is a valid and reliable measurement instrument for the evaluation of the occupational positive mental health.
\end{abstract}

\section{Keywords}

Positive Psychology, Occupational Health, Psychometric, Work

\section{Introduction}

For several decades, there has been an increasing interest in the development of a positive health and mental health approach. Authors such as Cannon (1932), pointed out that health is not a concept that should be measured based on the absence of sickness, but through the presence of abilities that function effectively in a specific situation, being necessary to develop positive indicators. Sigerist (1941) emphasized that the health and sickness characteristics are different and not necessarily opposed, stablishing the bases for the salutogenic model (Anto- 
novsky, 1979, 1987, 1996) and eugenesic model (Pando, 2012) by mentioning that the health field should focus on four areas: health promotion, sickness prevention, health restoration and rehabilitation. Maslow $(1954,1962)$ talked about a positive psychology, remarking the necessity of a new approach that included aspects such as human abilities and potentialities, along with the strategies for its development. The main contribution developed in this area, is the work of Jahoda (1958), who proposed a positive mental health construct where the sickness absence did not represent a primary indicator of health, being a concept composed by positive indicators such as positive attitudes, growth, development and actualization, integration of the person, autonomy, correct reality perception and environment dominium and control. Later, Csikszentmihalyi (1975, 1990), described a state of mental flow, in which the human being is capable of accomplishing total immersion in the develop activities, focusing on the energy in a way that implies a feeling of being absorbed in the task and getting success in its development, a state that can present in any type of activities, such as work, and that correlates with the subjective wellbeing and life satisfaction. Authors such as Antonovsky $(1979,1987,1996)$, remarked the necessity to develop research about the salutogenic factors that intervene in the health generation, referring to the existence of a positive health and focusing on health promotion.

The contributions from the International Labour Organization (1984), seem to be one of the first traces of the development of a positive approach in the occupational mental health, referring to the existence of wellbeing indicators and to a "positive" mental health status, as concepts poorly explored that needed more research and development of strategies to promote positive indicators. In this same topic, Pando (1989) proposed some indicators of mental health quality, framing them to the work environment, such as social awareness, ability to transform reality, self-esteem, life project, creativity, grouping, social networks, ability to give and receive affection, among others. More recently, Ashmos and Duchon (2000), referred that work environment represents a main source of community sense, a constant link with others and with the human necessity to get connectedness and contribution, proposing the existence of an spirituality at work composed by aspects such as the community conditions, work unity community, positive organization values, work unity, among others. Likewise, Peterson and Seligman (2003) proposed the existence of human virtues and strengths such as curiosity, love for learning, critical thinking, creativity, perspective, courage, perseverance, integrity, vitality, ability to love and being loved, generosity, emotional intelligence, civism, justice sense, leadership, among others.

Despite the existence of proposals that include a positive approach to mental health, the transition from the classic mental health concept to a more positive one is not yet concrete. Nowadays, we can find different proposes that consider the absence of psychopathology or mental disorder as main indicator of mental health, meanwhile others present, a reactive approach, in which, the real health promotion is set aside, focusing the attention to the prevention and restauration 
of health. Another important lack is that most of the research that have focus in mental health study, usually include general aspects of life, leaving aside the work environment, an important are for the human development.

The existing disagreement in the mental health definition hinders the development of valid and reliable measurement instruments for its evaluation. This limitation also affects the study of mental health in the occupational area, an important gap considering that work is an activity that covers most of the time and results essential for the human development.

As an alternative to the classic negative and mixed approaches, Vázquez-Colunga (2016) proposed a theoretic model for the study of the Occupational Positive Mental Health (OPMH). This model is based in different theoretic proposes, one of which is the positive psychology, from which were taken into consideration aspects such as the psychological wellbeing, happiness, strengths and human virtues. From the humanism, took elements such as the human abilities and potentialities development. The salutogenesis provided contributions about the creation of virtuous circles that promote the health increase. Finally, the ecological approach was taken in consideration for the promotion of mental health in the occupational environment, as a part of the systems that interact and affect each other (Vázquez-Colunga, 2016).

In this proposal, the occupational mental health is consider as a dynamic construct that differs from mental illness, but not antagonistically, considering them as coexisting entities. Because of this, the instruments that aim to measure the authentic mental health, cannot consider the inclusion of negative elements, since the existence of them, do not guarantee the nonexistence of positive indicators. A truly positive approach is proactive and arises from a salutogenic or eugenesic conceptualization, focusing in the generation of virtuous circles and not in the suppression of vicious circles, being center in the promotion of mental health, with the purpose to increase the quality of life and work wellbeing (Vázquez-Colunga, 2016).

When you aim to evaluate mental health, it is necessary to reach to the occupational area in a specific manner, because work influences significantly the changes in people's mental health, due to the great amount of time spent on it during human life. In this sense, the work place is a propitious environment for the promotion of mental health, if work is approach as a source of wellbeing and satisfaction. This situation increases the need to develop measurement instruments that allow the evaluation of occupational mental health from a positive approach.

In the model of Vázquez-Colunga (2016), OPMH is constituted by four dimensions: the cognitive dimension refers to the perception of work environment stimuli, regarding to the set of information and opinions that the person has about its work and its environmental conditions; the behavioral dimension, refers to the behavioral tendencies and intentions against the stimuli perceive at the work place; the socioemotional dimension, regard to the set of emotions, feeling and attitudes about the stimuli perceived at the work place, based on 
which, the person interacts intra and interpersonally; and, the spiritual dimension, that refer to the ability of the person to understand the sense and meaning of the work they are developing, as well as the aspects of their jobs that allow them to feel a sense of transcendence thru their work.

\section{Measurement Instruments for the Evaluation of Occupational Mental Health}

Although there are several measurement instruments with a positive approach, these deal with mental health from general aspects and usually do not include the occupational area. One of these proposes is the Cuestionario de Salud Mental Positiva (Positive Mental Health Survey), designed by Lluch (1999) from the theoretic proposal of Jahoda (1958). Others are the Mental Health ContinuumLong Form and the Mental Health Continuum-Short Form developed by Keyes (2002, 2008). Along with the Escala de Funcionamiento Psicológico Positivo (Scale of Positive Psychology Functioning) of Meriño and Privado (2015), as well as its several adaptations and validations for different populations.

Other set of instruments developed from a positive approach only evaluate partial aspects of mental health, most of which are not designed for the occupational area. Among these, we can find the survey Virtues in Action-Inventory of Strengths from Peterson and Seligman (2003), which evaluates the human virtues and the character strengths, along others oriented to the evaluation of the life quality, positive affect, psychological wellbeing and subjective wellbeing.

There are only few measurement instrument specifically designed for the work environment, most of which evaluate partial aspects of what we think it should be consider as occupational mental health from an authentic positive approach. Some of this are the survey Spiritually at Work, developed by Ashmos and Duchon (2000), as well as the Cuestionario de Satisfacción Laboral (Work Satisfaction Survey) from Meliá and Peiró (1989).

More recently, Buttler and Kern (2016), developed the PERMA Profiler Survey, based in the PERMA model of Seligman (2011), which includes 23 items that approach general aspects related to the wellbeing and human development. This instrument was adapted to the work environment as the PERMA Workplace Profiler (Butler \& Kern, 2016), including the previous 23 items adapted to the work place, of which four regard to negative aspects such as anger, anxiety, sadness and loneliness; and three remained the same, approaching general aspects not related to the work environment.

It is noteworthy that some of these measurement instruments are based in a mixed or even negative approaches of mental health, not being able to disconnect from the denial of a condition as main indicator of mental health, one of this is the Cuestionario de Bienestar Laboral General (General Work Wellbeing Survey) from Blanch, Sahagún, Cantera and Cervantes (2010).

In Mexico, there is no measurement instrument for the evaluation of positive occupational mental health, because of which, we aim to design and determine the psychometric properties of an instrument developed for the evaluation of 
this construct.

\section{Methodology}

\subsection{Participants}

The sample consisted of 740 working adults from different jobs, living in Guadalajara, Mexico. The participants were selected based in the criteria of having an active remunerated occupation, at least one year of working life, be present and agrees to participate at the moment of the data collection.

\subsection{Instrument}

The Occupational Positive Mental Health Survey (OPMH-40), is a multidimensional instrument with a self-administer format, developed to apply to different occupational activities (see Annexes). The survey evaluates positive aspects of mental health at work, such as the personal wellbeing at work, the positive interpersonal relationships in the workplace, the immersion at the task, the work empowerment, the working life philosophy and the personal strengths at work. The measurement instrument includes 40 items divided into four subscales: The Spiritual dimension, which includes 10 items that refer to the ability to understand the sense and meaning of the work developed, as well as the aspects of the work that allow the person to feel a sense of transcendence through its work. The Cognitive dimension, integrated by 10 items, includes questions about the perception of the stimuli present at the work environment, that is to say, the set of information, beliefs and opinions that a person has about their work and the environmental conditions in which it is developed. The behavioral dimension, including 10 items, approaches topics about the tendencies, dispositions and behavioral intentions against the stimuli perceived at the work environment. The socioemotional dimension, conformed by 10 items, defined as the set of emotions, feeling and attitudes against the stimuli perceived at the work environment, which allow the person to interact intrapersonal and interpersonally. All the items have a five point Likert response option, going from "totally disagree" to "totally agree".

\subsection{Procedure}

The OPMH-40 was applied to 740 participants, which answer the survey in a printed format during sessions developed at their work place, taking an average of 15 minutes to answer the survey. The applicators were previously trained for this purpose.

\subsection{Data Analysis}

We developed a database at the SPSS, version 22.0 program, coding the sociodemographic and employment data of the participants, as well as their answers to the OPMH-40. The analysis was divided in the following phases:

1) A study of the survey's factorial validity was conducted using an exploratory factor analysis with the factorization method of core components and Vari- 
max orthogonal rotation. The test of sample adequacy conducted was the Kaiser-Mayer-Olkin and the Barlettsphericity test.

2) The survey's reliability was calculated using the Cronbach's alpha coefficient.

\subsection{Ethical Considerations}

The Academic Council of the Interinstitutional Doctorate in Psychology registered the project. It adheres to international treaties on human research, as well as to the General Health Law of Mexico. We considered the voluntary participation, confidentiality and anonymity as ethical aspects for this research.

\section{Results}

The final simple consisted of $53.9 \%$ (399) females and $46.1 \%$ (341) males. The marital status was $67.9 \%$ (503) married or with a partner; the mean age was 37.05 (ED 13.08) years. The school level was, $8 \%$ (59) had a basic education, $20.5 \%$ (152) graduated from high school or a technical degree, $38.9 \%$ (288) attended college and $32.6 \%$ (241) had a master's degree. About the sector of employment, $45.8 \%$ (339) worked in the public sector and $54.2 \%$ (401) in the private sector, whit a mean of 14.13 (ED 10.8) years worked.

\section{Exploratory Factor Analysis}

The Kaiser-Mayer-Olkin $(\mathrm{KMO}=.918)$ and the Barlettsphericity test $(\mathrm{X} 2=$ 10755.47; $\mathrm{gl}=780 ; \mathrm{p}<.000)$, indicated that items intercorrelation was optimal for the development of the factor analysis. A four factor structure was extracted through the analysis, which explained $43.54 \%$ of the total variance of the survey (Figure 1).

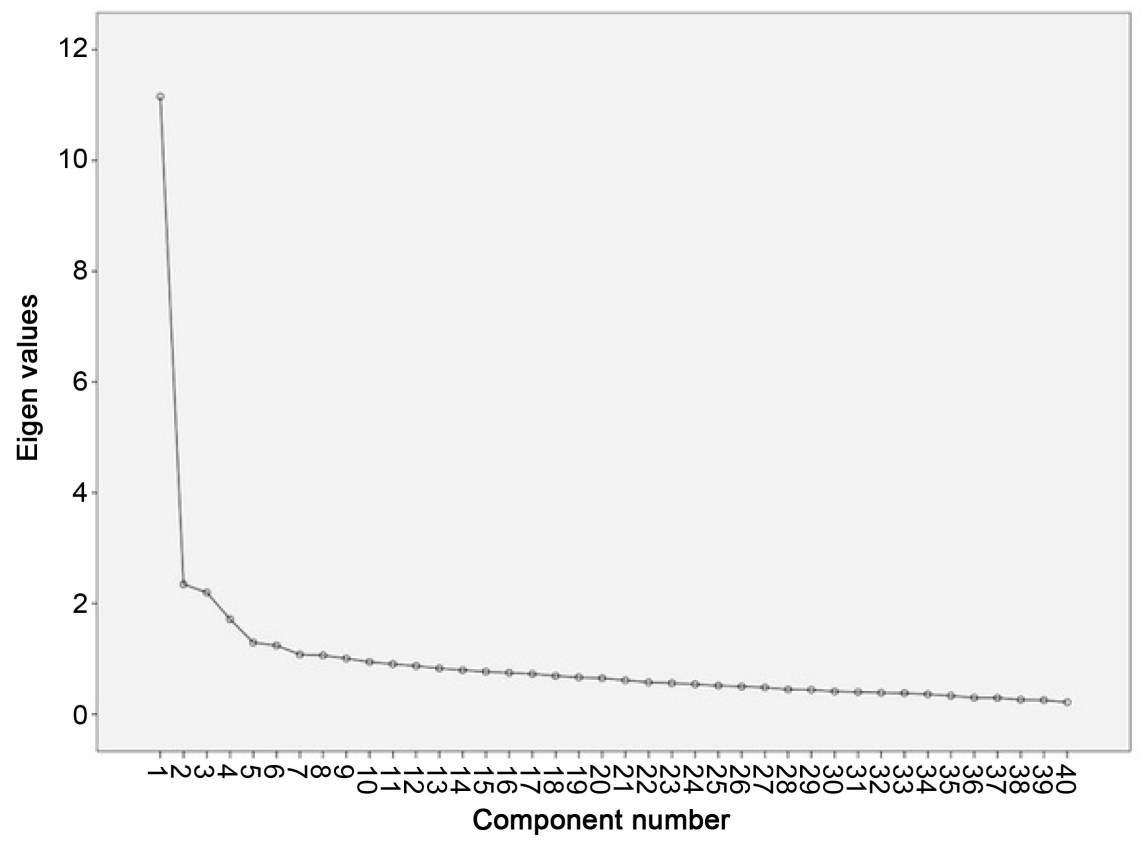

Figure 1. Scree plot of the OPMH-40. 
We proceed to apply the Varimax rotation to the items, presenting the results ordered by the eigenvalue. In the first component, named as Spiritual dimension, ten items were included with values from .735 to .499; in the second, named as cognitive dimension, ten items were grouped with values from .675 to .417; in the third, named as behavioral dimension, ten items were included with values from .707 to .426 ; in the fourth, named as socioemotional dimension, ten items were grouped with values from .661 to .439 (Table 1).

The reliability by dimension and for the complete survey is presented in Table 2. The results indicate that the four dimensions and the complete survey have a Cronbach's alpha higher than .7, considered as an indicator of high internal consistency.

\section{Discussion}

For more than three decades, the International Labour Organization (1984), talked about the necessity to stablish indicators of wellbeing and "positive" mental health at work. However, we can still find ambiguities about the positive indicators included in the occupational positive mental health evaluation, finding indicators as ingenuity, creativity, ability to solve problems, ego strength, adaptability, sociability, positive/negative attitude towards the future, among others. Considering this important lack in the existing research about occupational positive mental health, the aim of this research was to determine the psychometric properties of a measurement instrument design for the evaluation of this construct (OPMH-40). The results obtained indicate that this instrument has a four-dimension structure, consistent with the theoretical framework taken as base for the development of the survey, presenting high reliability values.

The first survey dimension is the spiritual component, in the factorial analysis, included ten items that regard to the sense of transcendence that an individual can reach through work. Árias, Macías, Muñoz and Arpasi (2015) define spirituality a human potentiality that leads to the individual happiness, increasing its commitment level and self-efficacy feeling. This concept was originally included in the study of occupational positive mental health by authors such as Ashmos and Duchon (2000), which instruments have acceptable validity and reliability, but have not been applied with Mexican population.

For the cognitive and behavioral dimensions, both with 10 items, we identify items related to the Escala de Funcionamiento Psicológico Positivo (Scale of Positive Psychological Functioning) of Meriño, Privado and Gracia (2015), which refer to beliefs, thoughts and value judgements, as well as behaviors or salutogenic intentions.

The socioemotional dimension includes 10 items as well, includes eudemonic and hedonic aspects based in the elements included in Seligman (2011), PERMA model, where $\mathrm{P}$ stands for positive emotions, E for engagement, $\mathrm{R}$ for relationships, $\mathrm{M}$ for meaning and $\mathrm{A}$ for accomplishments, elements taken as conceptual base of the OPMH- 40 .

Although, this is not the only instrument developed for the evaluation of 
Table 1. Factorial structure of the OPMH-40 (rotated component matrix)

\begin{tabular}{|c|c|c|c|c|}
\hline $\begin{array}{l}\text { SMPO } \\
\text { Items }\end{array}$ & $\begin{array}{l}\text { Espiritual } \\
\text { dimension }\end{array}$ & $\begin{array}{l}\text { Cognitive } \\
\text { dimension }\end{array}$ & $\begin{array}{l}\text { Behavioral } \\
\text { dimension }\end{array}$ & $\begin{array}{c}\text { Socioafective } \\
\text { dimension }\end{array}$ \\
\hline Item 28 & .734 & & & \\
\hline Item 22 & .722 & & & \\
\hline Item 18 & .702 & & & \\
\hline Item 9 & .62 & & & \\
\hline Item 8 & .597 & & & \\
\hline Item 13 & .594 & & & \\
\hline Item 3 & .586 & & & \\
\hline Item 20 & .568 & & & \\
\hline Item 23 & .523 & & & \\
\hline Item 21 & .499 & & & \\
\hline Item 12 & & .675 & & \\
\hline Item 11 & & .645 & & \\
\hline Item 15 & & .593 & & \\
\hline Item 38 & & .556 & & \\
\hline Item 26 & & .541 & & \\
\hline Item 14 & & .533 & & \\
\hline Item 35 & & .513 & & \\
\hline Item 39 & & .49 & & \\
\hline Item 31 & & .432 & & \\
\hline Item 40 & & .417 & & \\
\hline Item 4 & & & .707 & \\
\hline Item 16 & & & .619 & \\
\hline Item 19 & & & .594 & \\
\hline Item 6 & & & .57 & \\
\hline Item 7 & & & .566 & \\
\hline Item 1 & & & .517 & \\
\hline Item 5 & & & .496 & \\
\hline Item 25 & & & .469 & \\
\hline Item 29 & & & .458 & \\
\hline Item 2 & & & .426 & \\
\hline Item 24 & & & & .661 \\
\hline Item 30 & & & & .577 \\
\hline Item 33 & & & & .567 \\
\hline Item 17 & & & & .559 \\
\hline Item 34 & & & & .47 \\
\hline Item 32 & & & & .465 \\
\hline Item 27 & & & & .453 \\
\hline Item 36 & & & & .453 \\
\hline Item 37 & & & & .441 \\
\hline Item 10 & & & & .439 \\
\hline
\end{tabular}

a. Extraction method: Main component analysis. Varimax rotation of Kaiser. 
Table 2. Reliability and descriptive statistics of the OPMH-40.

\begin{tabular}{ccccc}
\hline Dimensions & Cronbach's alpha & Mean & SD & Item number \\
\hline Spiritual & .871 & 89.13 & 12.11 & 10 \\
Cognitive & .817 & 94.71 & 6.73 & 10 \\
Behavioral & .818 & 87.28 & 10.10 & 10 \\
Socioafective & .775 & 89.18 & 9.54 & 10 \\
Complete survey & .923 & 360.46 & 31.28 & 40 \\
\hline
\end{tabular}

a. Note: Standard Deviation (SD).

mental health from a positive approach, it is possible to say that the OPMH-40 is the only published measurement instrument focused in the occupational mental health from an authentic positive approach. In this sense, while the OPMH-40 is oriented to mental health at work, taking into consideration positive aspects of the occupational environment, other measurement instruments, such as the $\mathrm{Cu}$ estionario de Salud Mental Positiva (Survey for Positive Mental Health), designed by Lluch (1999), the Mental Health Continuum-Short form, developed by Keyes (2002, 2008), and the Escala de Funcionamiento Psicológico Positivo (Scale of Positive Psychological Functioning) of Meriño, Privado and Gracia (2015), represent proposal that are not designed for the occupational area, focusing in general aspects of the mental health.

The OPMH-40, the Mental Health Continuum-Long Form (Keyes, 2002) and the Cuestionario de Salud Mental Positiva (Positive Mental Health) from Lluch (1999) are very similar in extension-40 and 39 items respectively-the OPMH40 presents a higher reliability in the values obtained for the Cronbach Alpha Coefficient. The same situation applies for the Mental Health Continuum-Short Form (Keyes et al., 2008), and the Escala de Funcionamiento Psicológico Positivo (Scale of Positive Psychological Functioning) of Meriño, Privado and Gracia (2015).

On the other hand, more recently, Buttler and Kern (2016) developed the Survey PERMA Profiler, based in the PERMA model of Seligman (2011). The survey includes 23 items that approach general aspects of life related to wellbeing and human development. The original version was adapted for the occupational environment as the PERMA Workplace Profiler (Buttler \& Kern, 2016), retaking the 23 items and adapting them to work situations. It is important to say that in this version, only 16 items regard to positive elements of the work place; four items include negative aspects such as anger, anxiety, sadness and loneliness; while three remain the same as the original version, asking about general aspects of life. The socioemotional dimension of OPMH-40 can be equate with some elements of the PERMA Profiler survey, about positive emotions, relationships, meaning and accomplishment, because the conceptual basis of PERMA Profiler focuses on eudemonic and hedonistic aspects.

Regarding the cognitive and behavioral dimension of OPMH-40, we identify related elements in the Escala de Funcionamiento Psicológico Positivo (Scale of Positive Psychological Functioning) of Meriño, Privado and Gracia (2015), 
which refer to beliefs, thoughts and value judgments, as well as behaviors or salutogenic intentions.

Among the strengths of this research is the variety of occupations of the participants in the sample, which allow us to consider this as a generic measurement instrument, however, it would be important to develop future research that include comparisons between the different occupations, allowing to adapt specific versions for different work activities. The main limitations of this research are that we did not developed a comparison between this survey and other measurement instruments, also, the sample could be extended to 20 persons per item, adding a random and stratified sampling system. Likewise, it would be important to apply the survey to different cultural populations, in order to stablish measuring scales for the survey.

The OPMH-40 is an original contribution that represents an alternative to the existing measurement instruments, usually based in a negative or mixed posture, bringing closer the possibility of positive interventions that can promote the mental health in the work place.

\section{Conclusion}

The SMPO-40 is a valid and reliable measurement instrument for the evaluation of the occupational mental health that can be used with subjects of different work occupations.

The analysis developed for this research allows us to conclude that the SMPO40 has an acceptable construct validity. Among the instrument qualities are the high reliability and the short time of application. The SMPO-40 evaluates, from a positive approach, the occupational mental health, which can provide guidelines for the development of interventions strategies oriented for the authentic promotion of mental at the work environment.

\section{Acknowledgements}

To the participants in the research and the authorities of the different institutions that facilitated the data collection for the research. In addition, it would be important to acknowledge the University of Guadalajara and the Consejo Nacional de Ciencia y Tecnología (National Science and Technology Council CONACYT) for the support provided through the doctoral scholarship.

\section{References}

Antonovsky, A. (1979). Health, Stress and Coping. San Francisco: Jossey-Bass Publishers.

Antonovsky, A. (1987). Unravelingthemystery of Health. Howpeoplemanage Stress and Staywell. San Francisco: Jossey-Bass Publishers.

Antonovsky, A. (1996). The Salutogenic Model as a Theory to Guide Health Promotion. Health pomotion International, 11, 11-18. https://doi.org/10.1093/heapro/11.1.11

Árias, W., Macías, M. A., Muñoz, E., \& Arpasi, M. (2015). Spirituality in the Work Environment and Its Relation with the Happiness of the Worker. Revista de Investigación Arequipa, 4, 9-33. 
Ashmos, D. P., \& Duchon, D. (2000). Spiritualy at Work. A Conceptualization and Measure. Journal of Management Inquiry, 9, 134-145. https://doi.org/10.1177/105649260092008

Blanch, J. M., Sahagún, M. A., Cantera, L., \& Cervantes, G. (2010). Questionnaire of General Labor Well-Being: Structure and Psychometric Properties. Revista de Psicología del Trabajo y de las Organizaciones, 26, 157-170.

Butler, J., \& Kern, M. L. (2016). The PERMA-Profiler: A Brief Multidimensional Measure of Flourishing. International Journal of Wellbeing, 6, 1-48.

Cannon, W. B. (1932). The Wisdom of the Body. New York: W W Norton \& Co.

Csikszentmihalyi, M. (1975). Beyond Boredom and Anxiety. Washington: Jossey-Bass Publishers.

Csikszentmihalyi, M. (1990). Flow: The Psychology of Optimal Experience. New York: Harper and Row.

Jahoda, M. (1958). Current Concepts of Positive Mental Health. New York: Joint Commission on Menthal Illness and Health. https://doi.org/10.1037/11258-000

Keyes, C. L. M. (2002). The Mental Health Continuum: From Languishing to Flourishing in Life. Journal of Health and Social Behavior, 43, 207-222. https://doi.org/10.2307/3090197

Keyes, C. L. M., Wissing, M., Potgieter, J. P., Temane, M., Kruger, A., \& van Rooy, S. (2008). Evaluation of the Mental Health Continuum Short Form (MHC-SF) in Setswana.

Lluch, M. (1999). Construction of a Scale for the Evaluation of the Positive Mental Health. Non Published Doctoral Dissertation, España: The University of Barcelona.

International Labour Organization (1984). Psychosocial Factors at Work: Recognition and Control. Ginebra: ILO-WHO.

Maslow, A. H. (1954). Motivation and Personality. New York, NY: Harper \& Row Publishers.

Maslow, A. H. (1962). Toward a Psychology of Being. New York, NY: Harper \& Row Publishers. https://doi.org/10.1037/10793-000

Meliá, J. L., \& Peiro, J. M. (1989). The Measure of Job Satisfaction in Organizational Contexts: The Satisfaction Questionnaire 20/23. Psicologemas, 5, 59-74.

Meriño, M. D., Privado, J., \& Gracia, Z. (2015). Mexican Validation of the Positive Psychological Functioning Scale. Perspectives around the Study of Well-Being and Its Measure. Salud Mental, 38, 109-115.

Pando, M. (2012). Positive Mental Health. In M. Pando, C. Aranda, L. Parra, \& D. Ruiz (Eds.), Work Eugenics. Positive Mental Health at Work (pp. 15-29). Cali: Universidad Libre Seccional Cali.

Sigerist, H. (1941). Medicine and Human Welfare. Beloit, KS: McGrath Publishing Company.

Seligman, M. E. P. (2011). Flourish. A Visionary New Understanding of Happiness and Well-Being. New York, NY: Free Press.

Peterson. C., \& Seligman, M. E. P. (2003). Positive Clinical Psychology. In L. G. Aspinwall, \& U. M. Staudinger (Eds.), A Psychology of Human Strengths: Perspectives on an Emerging Field (pp. 305-317). Washington DC: American Psychological Association.

Vázquez-Colunga, J. C. (2016). Design, Validation and Reliability of a Multidimensional Survey for the Evaluation of the Occupational Positive Mental Health. Non Published Doctoral Dissertation. México: Universidad de Guadalajara. 


\section{Annexes}

Instructions: The following phrases include affirmations related to your work. To the right of each affirmation there is a space for you to mark your answer with an $\mathrm{X}$, using a values from 1 to 5 . One $(1)=$ Totally disagree. Two (2) = Disagree. Three (3) = undecided. Four (4) = agree. Five (5) Totally agree.

\section{Affirmation}

2

3

45

1. In times of labor uncertainty, I usually keep good expectations

2. I never let that a bad day at work affect my personal life

3. I have ideals at work that I would like to reach

4. At my work, I can face difficult situations remaining calm

5. I look for different solutions for the problems that arise at work

6. I am fully concentrated when I develop my work

7. I have the ability to adapt well to the changes in my work environment

8. My work is important because it contributes to the wellbeing of the others

9. My work contributes to give meaning to my life

10. With my example as a worker, I influence positively in my coworkers

11. Doing well my work satisfies me

12. I trust in my abilities as a worker

13. The work I develop makes me feel proud

14. I believe I am a worker with enough qualities

15. When something goes wrong at work, I continue straining

16. I am capable to maintain a good level of control in conflictive situations at work

17. I get on well with my coworkers

18. My work is related to the important things in life

19. I am capable of maintain a balance in my work performance against the external pressure

20. I have grown as a person through my work

21. I like to think in new ways for develop my work

22. My work helps me to feel fulfilled as a person

23. I am enthusiastic to develop my daily work activities

24. I consider myself a sociable person at work

25. I know clearly what am I supposed to do at work

26. I consider myself a competent worker

27. When I have work preoccupations, I let them know to someone that can help me

28. I feel passion to develop my work

29. I have a positive attitude towards myself at work

30. When I have problems at work, I seek for help in my coworkers.

31. I do my work activities because of my own choice

32. I really enjoy being a part of a work team

33. In my work, I enjoy being generous to others

34. Generally, I try to put some humor in the development of my work activities

35. Generally, I try to develop my work skills

36. I feel happy at work most of the time

37. Work is an important source of personal wellbeing

38. I think I am a trustworthy worker

39. Work is something that should be enjoyed

40. It is important to resolve the work conflicts in a positive manner 
Submit or recommend next manuscript to SCIRP and we will provide best service for you:

Accepting pre-submission inquiries through Email, Facebook, LinkedIn, Twitter, etc. A wide selection of journals (inclusive of 9 subjects, more than 200 journals)

Providing 24-hour high-quality service

User-friendly online submission system

Fair and swift peer-review system

Efficient typesetting and proofreading procedure

Display of the result of downloads and visits, as well as the number of cited articles Maximum dissemination of your research work

Submit your manuscript at: http://papersubmission.scirp.org/

Or contact psych@scirp.org 